\title{
ESPAÇOS LIVRES DE CONSTRUÇÃO
}

\author{
Fabiane dos Santos Toledo ${ }^{1}$, Douglas Gomes dos Santos ${ }^{2}$ \\ (recebido em 18.12.2007 e aceito pra publicação em 25.03.2008)
}

\section{RESUMO}

Os espaços livres de construção, dentre eles as áreas verdes têm a finalidade, além de suas próprias conservação e preservação, de proporcionar chances de lazer, recreação e o conseqüente aumento da qualidade de vida da população dos grandes centros urbanos. $O$ índice de áreas verdes nesses centros, expresso pela metragem quadrada de espaços livres de uso público relacionado ao número total de habitantes, revela fatores importantes naquelas funções, como por exemplo, elementos iniciais para o controle da quantidade dessas áreas e estratégias para a qualificação das mesmas. Por meio dessas análises considera-se que esses espaços só atingirão as funções destinadas a eles a partir de estratégias bem elaboradas e conduzidas pelo Poder Público juntamente com a comunidade. Para estudos e pesquisas relacionados a esse tema, é fundamental um sério levantamento teórico, o que, na bibliografia brasileira, ainda está em discussão por meio de vários autores e várias definições. Esta revisão tem o propósito de levantar e analisar conceitos relevantes no que se referem aos espaços livres de construção e traçar uma trajetória dos mesmos no Brasil através de seus históricos.

Palavras-chave: Espaços públicos livres, áreas verdes, parques urbanos, índice de áreas verdes.

\footnotetext{
1. Geógrafa, Universidade Federal de Uberlândia - UFU. Uberlândia, MG. E-mail: fabianests@hotmail.com

${ }^{2}$ Geógrafo, Prof. Dr. do Instituto de geografia - Universidade Federal de Uberlândia - UFU. Uberlândia, MG. E-mail: douglasantos@ig.ufu.br
} 


\section{THE OPEN SPACES}

\section{SUMARY}

The open spaces, between them the green areas, have the purpose, beyond their own conservation and preservation, of providing chances of leasure, recreation and the consequent increase in life quality of population in big urban centres. The rate of green areas in these centres, expressed by the square measure of free spaces of public uses related to the total number of habitants, reveals important factors on those functions, like example, initial elements for the control of quantity in these areas and strategies for the qualification of themselves. Through these analysis we consider that these spaces will only reach the functions destinated to them from the well done strategies and conducted by Public possession together with the comunity. For studies and researches related to this theme, it's essential a serious theoretical survey, which, in the Brazilian bibliography it is still in discussion by several writers and definitions. This revision has the purpose of raising and analysing relevant concepts that refer to the free spaces from construction and draw a tragetory of them in Brazil trough its historical.

Key-words: Open spaces, green areas, urban parks, rate of green areas. 


\section{INTRODUÇÃO}

As diferentes definições de termos técnicos como Espaço Livre, Área Verde, Parque Urbano, Índice de Área Verde e outros têm sido uma dificuldade tanto no meio científico quanto no planejamento e gestão desses espaços, certificando-se de que há a necessidade de se alcançar uma linguagem única em todos os campos. No entanto, sobre as áreas verdes, por exemplo, como bem afirmam Cavalheiro \& Del Picchia (1992), a literatura a respeito é escassa e conceitualmente muito genérica. Tal dificuldade, ou mesmo certa confusão acerca desses termos, pode ser explicada por meio da história, já que a discussão da necessidade de áreas verdes nas cidades começa a se efetuar na Revolução Industrial, na Inglaterra, França, Alemanha e Estados Unidos, conforme relatam diversos autores, citados por Lima et al. (1994), como Buchwald (1978), Richter (1981) e Tandy (1982) e Hennebo (1979); os autores refletem sobre um dos únicos espaços livres antes da Revolução Industrial, a Ágora de Atenas, na Antiguidade Clássica, onde se cultuavam os deuses e congregava a população para as discussões da política da república e que, ao contrário do que muitos acreditam, era um local arborizado. Assim, até a Revolução Industrial, as áreas verdes tinham uma função de representação para as autoridades e aristocracias, sendo que, com essa destinação não existiriam durante toda a Idade Média.

É de se compreender, portanto, a falta de esclarecimentos e definições precisas a respeito dos termos relativos a essas áreas, já que no decorrer da história os espaços das cidades medievais e renascentistas não eram arborizados, passando a ser somente a partir do século XIX, devido às preocupações das autoridades com a estética e com os problemas sanitários.

É relevante a diferenciação de Espaços Livres de Espaços Construídos e as diversas categorias e tipologias ligadas a eles. Diante disso, foi feito um levantamento perante a diversidade de definições existentes nas principais bibliografias para um melhor embasamento a respeito dos espaços livres de construção.

\section{Espaços Livres Públicos e Áreas Verdes}

\subsection{Breve histórico dos Espaços Livres no Brasil}

Embora o material histórico brasileiro seja escasso, ainda se destacam alguns fatos importantes sobre a inclusão dos espaços livres e áreas verdes em algumas regiões. $\mathrm{O}$ empenho por áreas verdes, referindo-se aos jardins, nasce somente no fim do século XVIII, com objetivo de preservação, provavelmente influenciado pela Europa, sendo mais freqüente no século XIX, ainda como herança dos países que já praticavam a arte do paisagismo; solicitando cada vez mais aos botânicos e paisagistas suas atividades 
profissionais. Dentre estes se destacam alguns como Auguste François Marie Glaziou, que veio ao Brasil a convite de D. Pedro II para ocupar o cargo de diretor geral de matas e jardins e permaneceu no Brasil por 39 anos, de 1858 a 1897, (TERRA, 2000).

Para Cavalheiro (1982) ainda existem no município de Recife esboços dos projetos dos jardins dos palácios de Friburgo e Bellevue, evidência da presença holandesa no Brasil, sendo a primeira amostra de paisagismo que se tem registro na História do país, mas que foi destruída com a expulsão dos mesmos. As praças, no domínio português, eram construídas com a finalidade de abrigar as principais edificações das vilas e cidades, usadas somente durante as festividades religiosas, sendo proibido o uso para outros fins.

O primeiro espaço livre proposital para Cavalheiro, op. cit., talvez tenha sido o "Passeio Público" da cidade do Rio de Janeiro construído no aterro da Lagoa do Boqueirão pelo Mestre Valentim, considerado o primeiro paisagista brasileiro. No Brasil ainda foram implantados projetos de melhoria urbana, principalmente com a vinda da Família Real Portuguesa, mas somente em meados do século XIX foi retomada a preocupação com os espaços livres, as áreas de nascentes foram reflorestadas surgindo, em uma dessas, a Floresta da Tijuca. Essas ações eram administradas pelos órgãos competentes e provavelmente tenha sido a primeira organização oficial a ter um espaço livre público na sua agenda.

De acordo com Lima (1993) e Segawa (1996) no final do século XVIII, o arquiteto naturalista Antônio José Landi teria plantado mangueiras nas ruas de Belém do Pará, com as finalidades de estudar e promover a adaptação da espécie ao novo ambiente; também a ação do senador Antônio José Lemos, conduzido à administração do município, permitiu desenvolver uma política urbana de intensa arborização e criação de parques e jardins.

Em São Paulo, com exceção da Estação da Luz, não houve esse desdobramento ou continuidade na administração desses espaços e somente depois de 1870 apareceram os espaços livres públicos, segundo Bruno, citado por Cavalheiro (1982).

A pesquisa histórica mostra, além da influência das áreas verdes sobre o desenho das cidades, a sobreposição existente entre esses campos. Além disto, elucida o momento em que os elementos vegetais passam a ser compreendidos como elementos estruturadores do espaço urbano, e têm sua força de tal forma adquirida, que passam a definir novas tipologias e estilos de paisagem e desenho urbano (FARAH, 1999).

Ainda no século XX, década de 1930, Roberto Burle Marx, pai do paisagismo tropical; artista plástico, pintor e escultor transforma o espaço urbano acrescentando o verde com diferentes formas e texturas na paisagem das cidades, usando harmoniosamente plantas nativas, tropicais e brasileiras, explorando a biodiversidade do país. Foi responsável pela criação de inúmeros jardins no país e no exterior, tais como o prédio da ONU em Nova York, o Jardim das Nações em Viena, o Aterro do Flamengo e o Museu de Arte Moderna no 
Rio de Janeiro, o Eixo Monumental de Brasília, o Aeroporto de Pampulha, em Belo Horizonte e o Parque do Ibirapuera, em São Paulo (FLEMING, 1996) ${ }^{3}$, citado por Andrade (2002).

Somente no final do século XX observa-se um interesse político pela implantação e formação de parques públicos. Iniciou-se, no final desse século, um processo crescente de implantação desse tipo de logradouro nos médios e grandes aglomerados urbanos, de responsabilidade tanto dos municípios, como dos governos estaduais (MACEDO; SARATA, 2003).

\subsection{Conceitos básicos sobre Espaços Livres Públicos e Áreas Verdes}

Os municípios brasileiros se constituem de áreas urbanas, de expansão urbana e rurais. Dentro das áreas urbanas estão os espaços de integração urbana (rede rodoferroviária), espaços com construções (habitações, indústrias, comércio, hospitais, escolas, etc.) e de espaços livres de construção (praças, parques, águas superficiais, etc.), definidos por Cavalheiro \& Del Picchia (1992).

Conforme relatam alguns pesquisadores, citados por Lima et al. (1994) e segundo Cavalheiro \& Del Picchia (op. cit.), é oportuno diferenciar Espaços Livres de Espaços Construídos e as diversas categorias e tipologias que congregam.

Para esses dois últimos autores, do ponto de vista conceitual, uma área verde é sempre um espaço livre e que este termo deveria ser preferido ao de área verde, por ser mais abrangente.

Outro termo a se explanar é o "Open Space" traduzido do inglês e tratado por alguns autores de forma diversa, Lima et al. (1994) cita:

Ainda na década de 1960, um trabalho de Eckbo, Rean Austin e Williams consideraram "open space" como uma área monitorada para a produção ou preservação de recursos naturais, para incremento da saúde, bem estar, conforto, segurança pública, corredores, e de expansão urbana. Mais tarde, o próprio Eckbo vem a definir "open space" como uma expressão genérica sobre muitos tipos de uso de solo.

Para existir espaço aberto em urbanismo, o termo utilizado deve ser área aberta. Os espaços livres desempenham papel ecológico, de integrador de espaços diferentes, baseando-se, tanto em enfoque estético, como ecológico e de oferta de áreas para o desempenho de lazer ao ar livre (CAVALHEIRO; DEL PICCHIA, op. cit.).

\footnotetext{
${ }^{3}$ FLEMING, L. Roberto Burle Marx, um retrato. Rio de Janeiro: Index, 1996. I60p.
} 
Ainda no trabalho de Lima et al. (1994) é colocado outro autor, Lapoix (1979) considerando Área Aberta, como espaços não construídos e não destinados a grandes infraestruturas, no interior e nas proximidades dos setores reservados à construção.

Segundo Cavalheiro \& Del Picchia (1992) espaço aberto é um anglicismo no qual a palavra "open space" (e não "free space") tem sido erroneamente traduzida, em português e ao pé da letra. Argumentam ainda que para existir espaço aberto em urbanismo, em português, deveríamos contar com o termo área aberta (que é bidimensional), para podermos dar-Ihe a tridimensionalidade que seria, então, espaço aberto. Apenas como exemplo, Lima et al. (op. cit.) em suas discussões ressalvam que, em suas pesquisas para a conclusão do trabalho houve a citação de que a diferença entre Área Livre e Espaço Livre é que este último tem que ter uma terceira dimensão, o céu, caracterizando-se por uma área descoberta, sem teto.

Sobre os espaços livres dentro da malha urbana, Cavalheiro \& Del Picchia (op. cit.) julgam necessários seus ordenamentos a fim de aperfeiçoar tais espaços tanto na oferta como na melhoria dos mesmos, propondo então que sejam classificados segundo sua tipologia, isto é, se são particulares, potencialmente coletivos (se seu acesso é permitido a uma comunidade restrita, como em clubes, pátios de escola e indústria, etc.) ou se são públicos. Posteriormente, devem ser classificados segundo suas categorias, como por exemplo: praças, parques, jardins, verde viário, etc. Ainda classifica-se quanto a sua disponibilidade: $\mathrm{m}^{2} /$ hab., área mínima, distância da residência, etc.

O conceito mais abrangente, então, dentro de uma pesquisa feita por Lima et al. (1994) seria o de Espaço Livre, integrando os demais e contrapondo-se ao espaço construído, em áreas urbanas. Assim, a Floresta Amazônica, citada como exemplo por aquela, não se inclui nessa categoria; já a Floresta da Tijuca (referida no histórico do Brasil como uma das primeiras áreas livres), localizada dentro da cidade do Rio de Janeiro, é um espaço livre. Não obstante esse conceito tem que ser integrado ao uso do espaço, sua escala e função, esta devendo cumprir três objetivos principais: ecológico, estético e de lazer.

Integrando as definições citadas e adicionando ao conceito adquirido por Sanchotene (2004), os espaços livres são as áreas não edificadas de uma cidade, de propriedade do Município, Estado, União ou de particulares, independentes de sua destinação de uso. Quando destinados à preservação ou implantação de vegetação ou ao lazer público, passam a se chamar áreas verdes, as quais podem ser praças, parques, jardins públicos, arborização urbana, etc. podendo ter vegetação de ocorrência natural ou implantada.

\footnotetext{
${ }^{4}$ LAPOIX, F. Cidades verdes e abertas. In: Ferry, M. G. Coord. Enciclopédia de Ecologia. São Paulo, EDUSP, 1979. P. 324-36.
} 
Sobre as áreas verdes, durante toda a pesquisa foi feita a constatação de que existe uma dificuldade com relação aos diferentes termos utilizados para elas, o que não foi diferente no contexto deste trabalho. No entanto, foi possível discernir algumas literaturas convergentes em relação à proposição deste.

Para início observa-se que o predomínio da vegetação é uma característica constante das áreas verdes, Milano (1992) discorre que:

...a vegetação presente nas cidades [...] é comumente tratada por área verde urbana e está estreitamente relacionada às áreas livres ou abertas; pode-se mesmo considerar que, embora nem toda área livre constitua área verde, toda área verde constitui área livre, mesmo que sua natureza e função sejam restritas[...] Por outro lado, adaptações ao conceito de espaços livres consideram estes como áreas verdes quando predominantemente não impermeabilizados e/ou com significativa cobertura vegetal.

É importante destacar que em um artigo publicado por Festi (2004) há a idéia de que as áreas verdes e os espaços de lazer são espaços com funções distintas e que, as prefeituras geralmente preferem denominar "espaço de lazer", pois podem fazer uso destes espaços públicos para a implantação de equipamentos urbanos de lazer, quadras esportivas, praças urbanizadas, etc., e para as secretarias estaduais de meio ambiente a preferência é das "áreas verdes", onde só é permitida a implantação de um "reflorestamento" da área com espécies de árvores nativas, tornando assim um espaço de preservação permanente, de interesse ecológico, mas que muitas vezes limita o acesso público para fins de recreação. No entanto, a maioria dos autores considera as áreas verdes como espaço também para o lazer, além de outras funções.

Foi desenvolvido um trabalho por Lima et al. (1994), no qual reuniu-se a comunidade científica, com a intenção de discutir a polêmica existente na definição de alguns termos técnicos, e para área verde concluiu-se o seguinte:

Onde há o predomínio de vegetação arbórea, engloba as praças, os jardins públicos e os parques urbanos. Os canteiros centrais de avenidas e trevos de vias públicas, que tem apenas funções estética e ecológica, devem, também, conceituar-se como área verde. Entretanto, as árvores que acompanham o leito das vias públicas, não devem ser consideradas como tal.

Com relação à tipologia, o mesmo trabalho especifica que como todo Espaço Livre, as Áreas Verdes também devem ser hierarquizadas, sendo (privadas, potencialmente coletivas e públicas), além de categorizadas, o que será evidenciado mais adiante.

Como já citado, para Cavalheiro \& Del Picchia (1992), do ponto de vista conceitual, uma área verde é sempre um espaço livre, incluindo que, para Geiser et al. (1975), citados por aqueles, dentro deste conceito incluem-se áreas com vegetação fazendo parte de 
equipamentos urbanos, parques, jardins, cemitérios existentes, áreas de "pequenos jardins", alamedas, bosques, praças de esporte, "playgrounds", "playlots", balneários, "camping" e margens de rios e lagos. Demattê (1997) emprega "áreas verdes" a diversos tipos de espaços urbanos, públicos ou particulares, que têm em comum: serem abertos, acessíveis e relacionados com saúde e recreação.

Franco (2001) diz que as Áreas Verdes são definidas também como:

descontinuidades de ocupação do tecido urbano necessárias para que os espaços sociais não se vejam comprometidos em sua função primordial que é a de serem o lugar de viver do homem e das comunidades, o que significa dormir, trabalhar, ter momentos de lazer, relacionar-se.

\subsection{Classificação das Áreas Verdes}

Como os espaços livres, as áreas verdes também devem ser classificadas segundo suas categorias, as quais variam para diferentes partes do Brasil e do mundo, argumentadas nas suas funções e nos seus projetos. No entanto, para Nucci (2001) as áreas verdes localizam-se na zona urbana e devem fornecer possibilidades de lazer à população; elas constituem um subsistema do sistema de espaços livres.

Dentre as categorias dos espaços livres merecem destaque os parques e as praças, estas definidas pela SBAU por meio de um artigo de Sanchotene (2004) como "área verde com dimensões, em geral, entre $100 \mathrm{~m}^{2}$ e 10 hectares, destinada ao lazer ativo ou passivo e para manifestações da sociedade, podendo ser dotadas ou não de vegetação." $E$ os parques como:

área verde com dimensões, a partir de 10 hectares, destinada ao lazer ativo ou passivo, à preservação da flora e da fauna ou de outros atributos naturais que possam caracterizar a unidade de paisagem na qual o parque está inserido, bem como promover a melhoria das condições de conforto ambiental nas cidades.

Inseridos na malha urbana, são os parques de bairro e distritais/setoriais, que cumprem as funções de lazer à população. Os parques de bairro devem possuir $6,0 \mathrm{~m}^{2} /$ habitante e uma área mínima de 10 ha (hectares) e os parques distritais ou setoriais devem possuir 6,0 a 7,0m²/habitante e uma área mínima de 100 ha (Cavalheiro; Del Picchia, 1992).

No trabalho de Lima et al. (1994) as categorias principais são:

Parque Urbano: é uma Área Verde, com função ecológica, estética e de lazer, entretanto com uma extensão maior que as chamadas Praças e Jardins Públicos. 
Praça: como Área Verde, tem a função principal de lazer. Uma praça, inclusive, pode não ser uma Área Verde, quando não tem vegetação e é impermeabilizada (caso das Praças da Sé e Roosevelt, na cidade de São Paulo); no caso de ter vegetação é considerada Jardim. Um Parque pode ter vários jardins, como é o caso dos jardins para deficientes visuais ou mesmo jardim japonês, entre outros, presentes no Parque do Ibirapuera, em São Paulo.

Para Wright et al. citados por Escada (1992) as funções dos espaços livres, mencionados aqui devido às relações com a vegetação, são agrupadas em três conjuntos distintos:

1. Espaços livres para recreação, que devem proporcionar recreação física e psicológica e oferecer um local onde o ser humano possa ter um ambiente adequado ao lazer. Esses espaços são sub-divididos em:

1.1. Parque de vizinhança que são áreas com função recreacional que podem abrigar alguns tipos de equipamentos ligados à recreação. São espaços livres pequenos inseridos no projeto de loteamento ocupando um ou mais lotes, devem conter vegetação, ambientes de jogos, bancos para descanso, etc. Para atender convenientemente a população devem estar entre 100 e 1000m de distância das residências ou do trabalho.

1.2. Parque de bairro, de maiores dimensões, além de terem funções recreacionais mais ativas, apresentam funções paisagísticas ou bioclimáticas, não são entendidos, ao contrário dos primeiros espaços, como extensão das residências.

1.3. Parque distrital, de grandes dimensões, são áreas de bosques que contam elementos naturais, de grande beleza, que devem ser conservados na condição original.

2. Espaços livres para a conservação de recursos biofísicos, são espaços que têm o objetivo de satisfazer às necessidades da sociedade em longo prazo. São espaços pouco ou não alterados destinados à proteção da água de abastecimento, preservação de enchentes pela absorção da água de declive acentuado, proteção de áreas de valor paisagístico, arqueológico ou biológico.

3. Espaços livres para o desenvolvimento da forma urbana, são os espaços que têm o objetivo de modelar o padrão do desenvolvimento urbano dando uma idéia de identificação e territorialidade, a título apenas de exemplo, pois não será discutido neste trabalho.

Somente para exemplificação, há ainda os autores que realizaram suas pesquisas considerando outros elementos (além das categorias e de área por habitante) como de disponibilidade, tempo de acesso ao espaço livre e faixa etária do público alvo. Alguns concluíram que a distância e o tempo gastos para se chegar nesses espaços associados à 
idade da população é fator relevante quanto a freqüência nessas áreas. Jantzen citado por Nucci (2001), sugere que, se esses espaços forem destinados a crianças de até 6 anos, devem estar situados a uma distância de até $100 \mathrm{~m}$ da habitação; de 6 a 10 anos, a até $500 \mathrm{~m}$; e de 10 a 17 anos a até 900m, além de outros itens, como mostra a Tabela 1.

Tabela 1 - Classificação apresentada por Jantzen.

\begin{tabular}{lcccc}
\hline TIPO & A. MIN. & DIST. da RESID. & ÍNDICE & PROPRIEDADE \\
\hline Unidade Vizinhança 0- 6 & 105 & 100 & 0,75 & Público ou Particular \\
Unidade Vizinhança 6-10 & 625 & 500 & 0,75 & Público ou Particular \\
Unidade Vizinhança 10-17 & 5.000 & 900 & 0,75 & Público ou Particular \\
Área Esportiva & 4.000 & 500 & 5,5 & Público ou Particular \\
Balneário & 2.000 & - & 1 & Público ou Particular \\
Acampamento & - & - & - & Público ou Particular \\
Jardins & - & - & 12 & Público ou Particular \\
Cemitério & - & - & 4,5 & Público ou Particular \\
Parque Bairro & 100.000 & 900 & 6 & Público \\
Parque Distrital & 1.500 .000 & 1200 & 7 & Público \\
\hline
\end{tabular}

Fonte: $\mathrm{NUCCl}(2001)$

Segundo Geiser et al. (1976), citado por Barbin (2003) existem espaços que não são ligados a recreação - áreas públicas ou não - relacionados à ornamentação, enriquecimento visual e outros, com menor importância quanto às interações com o meio ambiente, são os jardins internos, arborização de vias públicas, vegetação em canteiros centrais de avenidas, jardins e parques particulares, residenciais, industriais, etc.

O sistema de parques urbanos ou municipais pode ser de dois tipos: parques urbanos, dentro do perímetro urbano e parques rurais, situados dentro do município. Os parques municipais guardam uma correlação especial com os problemas sociais, proporcionando, por exemplo, a queda do índice de criminalidade infantil (CHADDAD, 2000).

Alguns dos atuais parques de pequeno porte não passam realmente de praças de vizinhança, sendo denominados parques em virtude da falta de consenso sobre o assunto entre os especialistas, dentro e fora do poder público (MACEDO; SARATA, 2003).

As Unidades de Conservação (UCs) incorporadas no SNUC dividem-se em dois grupos: Unidades de Proteção Integral e Unidades de Uso Sustentável, do primeiro é integrante a categoria de Parques Nacionais, que por sua vez reúne Parques Estaduais e Municipais, conforme preceitos abaixo:

Art. 11. O Parque Nacional tem como objetivo básico a preservação de ecossistemas naturais de grande relevância ecológica e beleza cênica, 
possibilitando a realização de pesquisas científicas e o desenvolvimento de atividades de educação e interpretação ambiental, de recreação em contato com a natureza e de turismo ecológico.

§ 1ํㅡ Parque Nacional é de posse e domínio públicos, sendo que as áreas particulares incluídas em seus limites serão desapropriadas, de acordo com o que dispõe a lei.

$\S 2^{0}$ A visitação pública está sujeita às normas e restrições estabelecidas no Plano de Manejo da unidade, às normas estabelecidas pelo órgão responsável por sua administração, e àquelas previstas em regulamento.

§ 30 A pesquisa científica depende de autorização prévia do órgão responsável pela administração da unidade e está sujeita às condições e restrições por este estabelecidas, bem como àquelas previstas em regulamento.

$\S 40$ As unidades dessa categoria, quando criadas pelo Estado ou Município, serão denominadas, respectivamente, Parque Estadual e Parque Natural Municipal.

Ademais, com relação ao Regulamento dos Parques Nacionais Brasileiros o Decreto no. 84.017 de 21 de setembro de 1979 ainda delibera:

Art. $2^{\circ}$ - Serão considerados Parques Nacionais as áreas que atendam às seguintes exigências:

I - Possuam um ou mais ecossistemas totalmente inalterados ou parcialmente alterados pela ação do homem, nos quais as espécies vegetais e animais, os sítios geomorfológicos e os "habitats", ofereçam interesse especial do ponto de vista científico, cultural, educativo e recreativo, ou onde existam paisagens naturais de grande valor cênico;

II - Tenham sido objeto, por parte da União, de medidas efetivas tomadas para impedir ou eliminar as causas das alterações e para proteger efetivamente os fatores biológicos, geomorfológicos ou cênicos, que determinaram a criação do Parque Nacional;

III - Condicionem a visitação pública a restrições específicas, mesmo para propósitos científicos, culturais, educativos, ou recreativos.

\section{2. Índice de Áreas Verdes}

Os índices de áreas verdes são expostos de diferentes formas por diferentes pesquisadores, para diferentes cidades, sendo talvez, uma conseqüência da falta de consenso entre os conceitos, já discutida neste trabalho. Cavalheiro \& Nucci (1998), alertam que o confronto de índices de áreas verdes entre cidades pode ser um equívoco, pois o índice desacompanhado da definição de termo "área verde" não estabelece parâmetros para comparações. Além disso, sabe-se que muitas administrações aumentam seus índices colocando todo espaço não construído como área verde e/ou até consideram a projeção das copas das árvores sobre as calçadas. 
No entanto, em termos gerais, o índice de áreas verdes é aquele que denota a quantidade de espaços livres de uso público, em $\mathrm{Km}^{2}$ (quilômetro quadrado) ou $\mathrm{m}^{2}$ (metro quadrado) dividido pela quantidade de habitantes de uma cidade. Para Sanchotene (2004), entende-se por índice de área verde por habitante a relação entre a densidade populacional e a metragem quadrada total de áreas verdes de uma cidade ou de partes dela. Acrescentando-se que para Guzzo (2003), apud Rondino (2005) essa matemática é feita entre os espaços nos quais o acesso da população é livre, ou seja, as praças, os parques e os cemitérios. Para aquele autor o índice deveria, primeiramente, ser calculado em função da quantidade total das áreas existentes e posteriormente, recalculado, demonstrando quantas dessas áreas estão sendo realmente utilizadas, após uma avaliação do seu estado de uso e conservação. Todavia, este índice está intimamente ligado à função de lazer que desempenham ou que venham a desempenhar.

Nucci (2001) afirmou que, para calcular o índice de área verde, devem ser consideradas somente as áreas verdes públicas localizadas na zona urbana e ligadas ao uso direto da população residente nessa área.

Cavalheiro \& Del Picchia (1992) referem-se ao índice mais difundido no Brasil, o qual teria sido desenvolvido pela Organização Mundial de Saúde (OMS), pela ONU e pela Organização das Nações Unidas para a Alimentação e a Agricultura (FAO), que considerariam como ideal que cada cidade dispusesse de $12 \mathrm{~m}^{2}$ de área verde/habitante. Porém, os autores mencionados e a ONU não o admitem. A Sociedade Brasileira de Arborização Urbana (SBAU) propôs como índice mínimo para áreas verdes públicas destinadas à recreação o valor de $15 \mathrm{~m}^{2} /$ habitante (SBAU, 1996). Para Escada (1987), os índices são instrumentos que devem ser utilizados como guia para questões muito complexas e por isso são muito subjetivos.

Oliveira (1996) fez um levantamento das áreas públicas do município de São Carlos/SP e obteve dois índices diferentes, o primeiro, chamado percentual de áreas verdes (PVA), foi estimado para grandes áreas da cidade, no qual entraram todas as áreas verdes públicas da cidade, sem contar a acessibilidade da população. Posteriormente, foi calculado o índice de áreas verdes (IAV), considerando somente as áreas verdes públicas de acesso livre para a população. $O$ índice de áreas verdes para a cidade como um todo também foi calculado e considerado um indicador de qualidade de vida da população.

Como exemplo, pode-se utilizar a fórmula de cálculo seguinte, a qual considera o somatório total das áreas verdes urbanas, expresso em metro quadrado, aqui nas categorias parques e praças, dividido pelo número de habitantes da área urbana, conforme a seguinte fórmula: 
TAVC $=\Sigma$ áreas de parques $\left(\mathrm{m}^{2}\right)+\Sigma$ áreas de praças $\left(\mathrm{m}^{2}\right)$

$\mathrm{IAV}=\frac{\mathrm{TAVC}}{\mathrm{NH}}$

Onde:

TAVC = Total de áreas verdes consideradas (parques e praças)

IAV = Índice de área verdes

$\mathrm{NH}=$ Número de habitantes

\subsection{Considerações sobre a importância das áreas verdes}

Conforme dizem Geiser et al. (1976), apud Barbin (2003) o impacto do homem sobre o meio ambiente faz-se em grande intensidade, o que pode repercurtir em concorrência da cidade com o espaço verde, representado pela vegetação, com a substituição desta pelo piso urbano. Segundo Oliveira (1996), áreas verdes são conceituadas como áreas permeáveis (sinônimo de áreas livres) públicas ou não, com cobertura vegetal predominantemente arbórea ou arbustiva (excluindo-se as árvores no leito das vias públicas) que apresentem funções potenciais capazes de proporcionar um microclima distinto no ambiente urbano em relação à luminosidade, temperatura e outros fatores associados ao bem-estar humano (funções de lazer); com significado ecológico em termos de estabilidade geomorfológica e amenização da poluição e que suporte uma fauna urbana, principalmente aves, insetos e fauna do solo (funções ecológicas); representando também elementos esteticamente marcantes na paisagem (função estética); independentemente da acessibilidade a grupos humanos. Além das funções social, ecológica e estética, as áreas verdes também podem auxiliar na educação e até na psicologia dadas as vantagens do elemento anti-estresse.

Os benefícios atuais são variados, resumidamente representados pela Figura 1, e dentre os efetivados de ação direta pelas as áreas verdes ratifica-se alguns considerados por Sanchotene (2004):

- Promoção de conforto térmico pela diminuição das temperaturas;

- Diminuição do consumo de energia nos centros urbanos;

- Resfriamento por sombreamento e evapotranspiração;

- Promoção da melhoria da qualidade do ar, através da geração de oxigênio na atmosfera, diminuição do gás carbônico, e adsorção de partículas poluentes; 
- Promoção da estabilidade climática;

- Enriquecimento do solo por acréscimo de matéria orgânica e dos nutrientes aumentando a fertilidade do mesmo;

- Controle da erosão pela proteção que o sistema radicular da vegetação confere ao solo;

- Manutenção de umidade no solo;

- Proteção das áreas de captação de água;

- Controle de inundações;

- Controle da poluição sonora;

- Conforto lumnico;

- Promoção da biodiversidade favorecendo a conservação da vida silvestre, oportunizando a propagação de espécies nativas;

- Promoção do desenvolvimento sustentável, prejudicado pela urbanização.

E dentre os benefícios indiretos citados pela mesma autora ainda existem:

- Lazer e Recreação;

- Ecoturismo;

- Melhoria das relações humanas psico-sociais, promovendo a saúde mental e física das pessoas;

- Educação;

- Valorização monetária de propriedades circundantes;

- Fortalecimento da organização comunitária.

Nucci (2001) também considera:

As áreas verdes estabilizam as superfícies por meio da fixação do solo pelas raízes das plantas; criam obstáculos contra o vento; protegem a qualidade da água, pois impedem que substâncias poluidoras escorram para os rios; filtram o ar; diminuem a poeira em suspensão; equilibram os índices de umidade no ar; reduzem o barulho; abrigam a fauna; contribuem para a organização e composição de espaços no desenvolvimento das atividades humanas; colaboram com a saúde do homem e também atenuam o impacto pluvial, auxiliando na captação de águas pluviais, tendo em vista que a impermeabilização crescente e progressiva do solo prejudica o escoamento superficial, não tendo a rede de captação de águas pluviais capacidade 
suficiente para escoar de modo rápido o grande volume de água que faz transbordar os córregos e se acumula nos vales do sítio urbano.

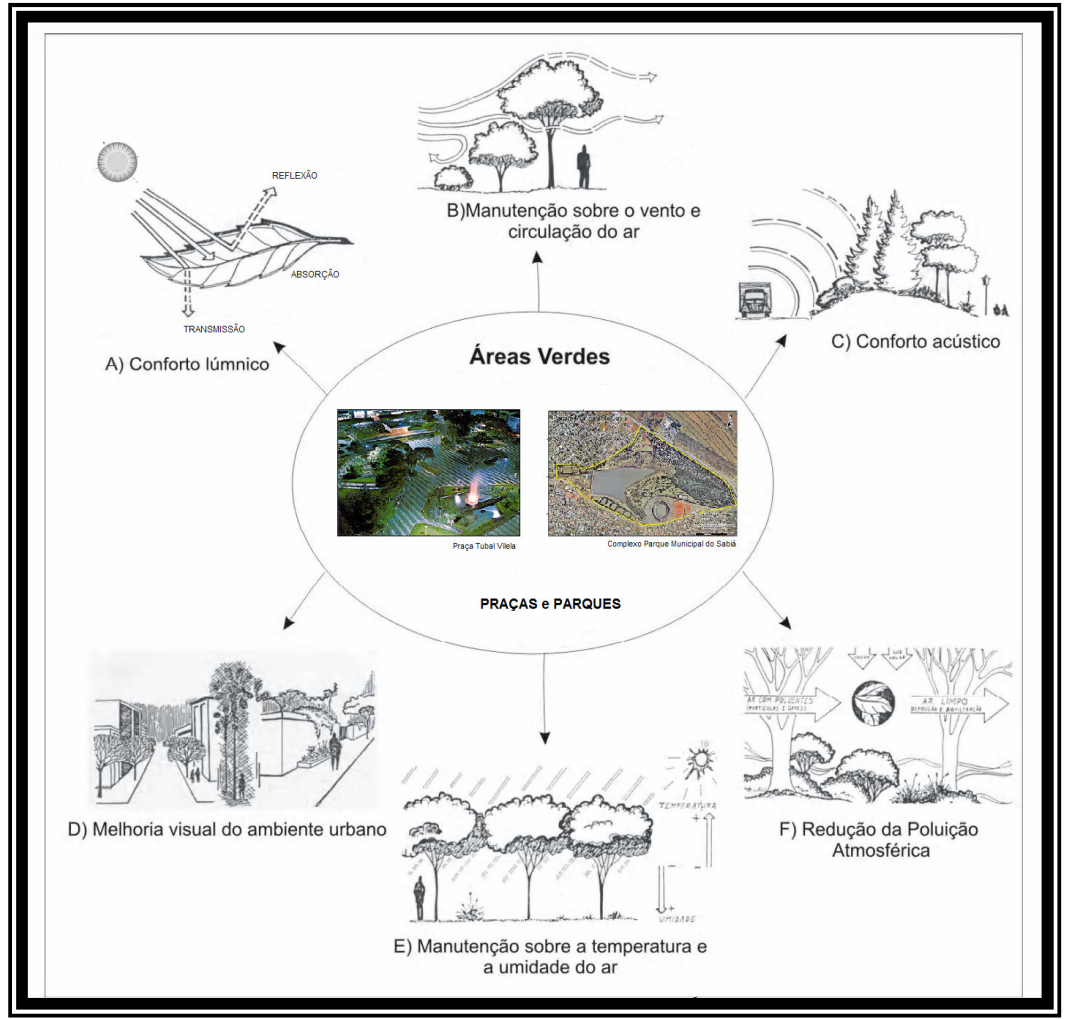

Figura 1 - Benefícios proporcionados pelas Áreas Verdes Urbanas - Parques e Praças.

Fonte: Rosset, 2005 (Org.: TOLEDO, F. 2006)

A criação de áreas verdes como parques e praças, na zona urbana dos municípios, auxilia no aumento da qualidade de vida da população, perdida nos grandes centros, ampliando o índice de área verde por habitante nos municípios.

Além de tudo isso, a finalidade dos espaços verdes livres é a plena expansão das funções de lazer e recreação. Recrear é voltar a criar energias. Todo homem deve ter possibilidade de escolher como recrear; há, portanto, necessidade de existir um sistema adequado de recreio para todas as classes e idades, compreendendo diversas alternativas, Rondino (2005).

Embora as pessoas tenham dificuldade em reconhecer o papel ambiental desempenhado pelo verde urbano, elas se sentem agraciadas ao caminhar sob árvores, usufruir sua sombra, caminhar sobre gramados, observar plantas em florescimento, admirar o canto dos pássaros (NUCCI, 1996).

Um dos elementos fundamentais para recreio são os parques, que devem ser objeto de estudo dos governos federal, estadual e municipal. No âmbito federal, os elementos de recreio são constituídos de uma cadeia de parques nacionais (CHADDAD, 2000). 
Para a conceituação de lazer e recreação Colesanti (1994) menciona ser necessário fazer a distinção entre esses dois termos, sendo o primeiro considerado o tempo disponível das pessoas após uma jornada de trabalho e o segundo como uma variedade muito grande de atividades realizadas neste tempo disponível desde assistir televisão até a prática de esportes. Rondino (2005) diz que o lazer abrange uma gama de possibilidades, tais como repousar, comer, fazer visitas, cinema, estádio, rádio, televisão, etc.; já a recreação é uma forma de transformar os momentos de folga para não se deixar cair no ócio. Dessa forma, o sistema de espaços livres públicos tem uma grande parcela de responsabilidade em fornecer opções para que a população encontre, nos momentos de lazer, muitas possibilidades de escolha para a sua recreação ao ar livre.

\subsection{Densidade populacional e áreas verdes}

Com o surgimento espontâneo e o crescimento rápido e desordenado das cidades, a vegetação natural foi, aos poucos, sendo substituída por elementos da infra-estrutura urbana constituídos basicamente por concreto, cerâmica, metais, vidro e asfalto. As cidades, ao terem seus componentes urbanos construídos com esses materiais, têm como resultante as superfícies com elevado índice de reflexão, bem como a impermeabilidade quase total dos solos, Barbin (2003).

A alta concentração da população gera a deterioração da qualidade de vida urbana acarretando o desconforto da mesma por meio da deficiência no abastecimento em geral, problemas na eliminação e deposição de lixo, ruídos, poluição, congestionamentos, competição, escassez de espaços livres para o lazer e falta de participação popular. Sendo este um problema que atinge a maioria das cidades de médio a grande porte, questiona-se um número que expresse a densidade populacional ideal (NUCCI, 1996). Para este autor, o número ideal para a densidade populacional varia entre 100 e 500 habitantes/ha.

Buscando as origens da crise urbana e, conseqüentemente, da ambiental atual, terse-ia que procurar as causas e o período em que começaram a se dissolver os limites da cidade e as mudanças sócio-culturais que acompanharam essa dissolução. No final do século XIX e início do século XX, aproximadamente, já com a Revolução Industrial, devido ao crescimento da área do município, o aumento populacional e a expansão da zona urbana, a cidade transformou-se em joguete dos interesses da especulação financeira e imobiliária. Segundo Lima (1991), surge o "urbanismo moderno" baseado em quatro objetivos fundamentais:

- Descongestionar o centro das cidades para cumprir as exigências de fácil circulação;

- Aumentar a densidade do centro das cidades para realizar o contato exigido pelos negócios oriundos no crescente mundo capitalista; 
- Aumentar os meios de circulação, ou seja, modificar as dimensões das ruas, que se encontravam sem efeito diante dos novos meios de transporte e;

- Aumentar as chamadas "áreas verdes" visando gerar maior lazer e menor estresse aos novos trabalhadores urbanos.

Segundo Guzzo (1999), as cidades são constituídas, do ponto de vista físico, de espaços de integração urbana, espaços construídos e espaços livres. [...] visando uma integração da natureza com a cultura do ser humano. Para tal, é necessário que se tenha idéia das alterações ambientais provocadas pela urbanização.

\section{CONSIDERAÇÕES FINAIS}

A revisão conceitual mostra que a discussão sobre espaços livres de construção é promissora em termos urbanísticos, mesmo com a pouca bibliografia a respeito no Brasil.

O histórico revela a influência das áreas verdes sobre o espaço geográfico das cidades esclarecendo e considerando os elementos vegetais como elementos de alicerce do espaço urbano. Pode-se concordar com Cavalheiro \& Del Picchia (1992) ao afirmarem que os espaços livres desempenham papel ecológico, de integrador de espaços diferentes, baseando-se, tanto em enfoque estético, como ecológico e de oferta de áreas para o desempenho de lazer ao ar livre. Um espaço livre tem que ser integrado ao uso do espaço, sua escala e função, esta devendo cumprir três objetivos principais: ecológico, estético e de lazer.

As áreas verdes, espaços destinados à preservação ou implantação de vegetação ou ao lazer público, têm papel fundamental na qualidade de vida da população e como bem defende Nucci (2001) as áreas verdes localizam-se na zona urbana e devem fornecer possibilidades de lazer à população; elas constituem um subsistema do sistema de espaços livres. A criação e manutenção desses espaços é de extrema relevância ao meio ambiente da área urbana, prejudicado nos grandes centros.

\section{REFERÊNCIAS}

BARBIN, H.S. Histórico da evolução do uso do solo e estudo dos espaços livres públicos de uma região do municipio de Piracicaba, SP. Tese (Doutorado em Agronomia) Piracicaba, 2003.

CAVALHEIRO, F. O planejamento de espaços livres: o caso de São Paulo. In: Congresso nacional sobre essências nativas, Campos do Jordão, 1982. Anais. São Paulo: Silvicultura em São Paulo, 1982. p. 29-38. 
CAVALHEIRO, F. \& DEL PICCHIA, P.C.D. Áreas Verdes: conceitos, objetivos e diretrizes para o planejamento. In: Congresso brasileiro sobre arborização urbana, I, Vitória/ES. Anais I e II. 1992. P.29-35.

CAVALHEIRO, F.; NUCCI, J.C. Espaços livres e qualidade de vida urbana. Paisagem Ambiente Ensaios, n.11, p. 277-88, 1998.

CAVALHEIRO, F.; NUCCI, J.C; GUZZO, P.; ROCHA, Y.T. Proposição de terminologia para o verde urbano. Boletim Informativo da Sociedade Brasileira de Arborização Urbana, Rio de Janeiro, n. 3 - Jul/ago/set de 1999. Rio de Janeiro, p.7.

ESCADA, M. I. S. Caracterização dos espaços livres de uso público de São José dos Campos. Rio Claro: UNESP, Instituto de Biociências, 1987.

FRANCO, R.M. Áreas Verdes: criação e manutenção. In: IBAM. FEPAM. SEMA. Programa de gestão Ambiental Compartilhada Estado/Município: elaboração de Plano Diretor de Desenvolvimento Urbano (em apoio à gestão ambiental). Porto Alegre: 2001.

FESTI, A.V. Os Critérios de Área Verde e Sistema de Lazer no Planejamento Urbano. In: Congresso brasileiro de cadastro técnico multifinalitário. COBRAC 2004. Florianópolis, UFSC, 2004.

LIMA, A.M.L.P.; CAVALHEIRO, F.; NUCCI, J.C.; SOUZA, M.A.L.B.; FIALHO, N.O ; DEL PICCHIA, P.C.D. Problemas de utilização na Conceituação de termos como espaços livres, áreas verdes e correlatos. In: Congresso Brasileiro sobre Arborização Urbana, 2, São Luiz/MA, 1994. Anais. p. 539-550.

MACEDO, S.S.; SARATA, F.G. Parques urbanos no Brasil. 2.ed. São Paulo: Edusp, 2003. 206p.

MILANO, M. S. A cidade, os espaços abertos e a vegetação. In: Congresso brasileiro sobre arborização urbana, I, Vitória/ES. Anais I e II. 1992. P. 03-14.

NUCCI. J.C. Qualidade ambiental \& adensamento urbano: Um estudo de ecologia e planejamento da paisagem aplicado ao distrito de Santa Cecília (MSP). São Paulo: Humanitas, 2001. 
OLIVEIRA, C.H. Planejamento ambiental na cidade de São Carlos/SP com ênfase nas áreas públicas e áreas verdes: diagnóstico e propostas. Dissertação (Mestrado) UFSCar, São Carlos, 1996. 181 p.

RONDINO, E. Áreas verdes como redestinação de áreas degradas pela mineração: estudo de casos nos municípios de Ribeirão Preto, Itu e Campinas, Estado de São Paulo. Dissertação (Mestrado em Agronomia) ESALQ - Escola Superior de Agricultura Luiz De Queiróz USP. Piracicaba, 2005. 126p.

ROSSET, F. Procedimentos metodológicos para estimativa do índice de áreas verdes públicas. Estudo de caso: Erechim, RS. Dissertação (Mestrado) São Carlos: UFSCar, 2005. Dissertação (Mestrado). Universidade Federal de São Carlos, 2005.

SANCHOTENE, M. do C.C. Conceitos e Composição do índice de áreas verdes. Boletim Informativo da Sociedade Brasileira de Arborização Urbana, n.1, p.4-9, 2004.

SEGAWA, H. Ao amor do público: jardins no Brasil. São Paulo: Studio Nobel, 1996. $240 p$.

TERRA, C. G. Os jardins no Brasil no século XIX: Glaziou revisitado. 2. ed. Rio de Janeiro: EBA, UFRJ, 2000. 